\title{
The effects of ERCC1 expression levels on the chemosensitivity of gastric cancer cells to platinum agents and survival in gastric cancer patients treated with oxaliplatin-based adjuvant chemotherapy
}

\author{
YONG-PING LIU ${ }^{1 *}$, YANG LING ${ }^{1 *}$, QIU-FENG QI $^{1}$, YA-PING ZHANG ${ }^{1}$, CHANG-SONG ZHANG $^{1}$, \\ CHANG-TAI ZHU ${ }^{1}$, MEI-HUA WANG ${ }^{2}$ and YAO-DONG PAN ${ }^{3}$ \\ ${ }^{1}$ Clinical Oncology Laboratory; ${ }^{2}$ Department of Pathology; ${ }^{3}$ Department of Gastroenterological Surgery, \\ Changzhou Tumor Hospital Affiliated to Suzhou University, Changzhou 213002, P.R. China
}

Received October 4, 2012; Accepted December 24, 2012

DOI: $10.3892 / 01.2012 .1096$

\begin{abstract}
Excision repair cross-complementing 1 (ERCC1) is reported to be involved in the sensitivity of cancer cells to platinum-based chemotherapy. The present study was designed to evaluate the effects of ERCC1 expression on the chemosensitivity of platinum agents in gastric cancer cell lines, and on survival in gastric cancer patients treated with surgery followed by oxaliplatin-based adjuvant chemotherapy. ERCC1 expression levels were measured by quantitative reverse transcription-polymerase chain reaction (qRT-PCR) and western blot analysis, respectively. The chemosensitivity of a series of gastric cancer cell lines to platinum agents in vitro was evaluated using CellTiter 96 Aqueous One Solution Cell Proliferation Assay kit. The apoptotic effect of the drugs was evaluated by double staining with Annexin-V-fluorescein isothiocyanate (FITC) and propidium iodide (PI). The results demonstrated that the expression levels of ERCC1 mRNA were correlated with the chemosensitivity of platinum agents, and depletion of ERCC1 sensitized the relatively resistant MKN45 cells to cisplatin and oxaliplatin. Univariate analyses revealed that patients with low ERCC1 levels had longer relapse-free survival (RFS) and overall survival (OS) than those with high ERCC1 levels (median RFS, 18 vs. 7 months, $\mathrm{P}=0.001$; median OS, 27 vs. 11 months, $\mathrm{P}=0.001$ ). Multivariate analyses suggested that high ERCC1 expression is an independent
\end{abstract}

Correspondence to: Dr Yong-Ping Liu, Clinical Oncology Laboratory, Changzhou Tumor Hospital Affiliated to Suzhou University, North Huaide Road No. 1, Changzhou 213002, P.R. China E-mail: liuyongping026@yahoo.com.cn

*Contributed equally

Key words: excision repair cross-complementing gene 1, gastric cancer, chemosensitivity, adjuvant chemotherapy, platinum, prognostic factor prognostic marker of poor RFS [hazard ratio (HR), 2.16; 95\% confidence interval (CI), 1.09-4.25; $\mathrm{P}=0.026]$ and $\mathrm{OS}$ (HR, 2.21; 95\% CI, 1.07-4.55; $\mathrm{P}=0.031)$. These results suggest that overexpression of ERCC1 is correlated with platinum drug resistance in gastric cancer cells, and that depletion of ERCC1 sensitizes gastric cancer cell lines to cisplatin and oxaliplatin. Gastric cancer patients with low levels of ERCC1 expression demonstrate a benefit from oxaliplatin-based adjuvant chemotherapy.

\section{Introduction}

Despite its declining incidence, gastric cancer remains the second most common cause of cancer-related mortality in Asia and worldwide $(1,2)$. Surgery remains the mainstay of any curative treatment. However, even following radical surgery, the majority of gastric cancer patients develop local or distant recurrence (3). Several meta-analyses of postoperative adjuvant trials have demonstrated a significant benefit for chemotherapy-treated patients (4). However, certain patients have undergone expensive and potentially harmful therapy without gaining any benefit. Thus, the identification of molecular markers in resected tumor tissues that are able to predict outcomes is essential for the future development of adjuvant chemotherapy for gastric cancer patients.

Cisplatin is widely used and has been demonstrated to be effective in the palliative treatment of gastric cancer, and different combinations have been investigated in the adjuvant setting $(5,6)$. Oxaliplatin (cis-[oxalate (trans-1-1, 2-diaminocyclohexane) platinum (II)]), a third-generation platinum compound, has been observed to be more effective than cisplatin (7), and has a more favorable toxicity profile than cisplatin (8). Thus the oxaliplatin plus 5-fluorouracil (5-FU) modulated with leucovorin (LV) (FOLFOX regimen) has been widely used as the first-line treatment in advanced gastric cancer (9-13). However, resistance to oxaliplatin and cisplatin remains a major obstacle to further increasing the response rate. Additionally, the involvement of the FOLFOX regimen in combination with surgery to increase local control or prolong 
survival also requires further investigation in resected gastric cancer.

DNA repair capacity is considered to be both a barrier to carcinogenesis and a crucial molecular pathway implicated in resistance to platinum-based chemotherapy (14). The cytotoxic effect of anticancer platinum drugs is principally attributable to the formation of platinum-DNA adducts (15). Nucleotide excision repair (NER) is the primary DNA repair mechanism that removes platinum-DNA adducts from genomic DNA. Excision repair cross-complementing 1 (ERCC1) is a critical gene in the NER pathway (16). ERCC1 is highly conserved during evolution and is constitutively expressed in all tissues at relatively high levels. A functional ERCC1 is essential for survival; knockdown of the ERCC1 gene in mice was observed to lead to an accelerated-aging phenotype, with brain damage, liver failure and death occurring shortly after weaning (17). A growing body of evidence has demonstrated that the ERCC1 gene acts as both a predictive and a prognostic marker $(18,19)$. It has been demonstrated in several clinical studies that ERCC1 messenger RNA expression in various types of cancer, including ovarian, colorectal, gastric and esophageal cancer, as well as non-small cell lung cancer (NSCLC), is correlated with clinical resistance to platinum agents (20-23). However, a limited number of gastric cancer studies have focused on the effect of ERCC1 expression on the outcome of FOLFOX adjuvant chemotherapy.

The aim of this study was to evaluate the effect of ERCC1 expression levels on the chemosensitivity of platinum agents in gastric cancer cell lines, and to evaluate whether ERCC1 expression levels are correlated with survival in gastric cancer patients treated with surgery followed by oxaliplatin-based adjuvant chemotherapy.

\section{Materials and methods}

Cell lines and cultures. The human gastric cancer cell lines, including AGS, NCI-N87, BGC-823, HGC and MKN45, were obtained from the Shanghai Institute of Cell Biology (Shanghai, China). All cell lines were propagated in Roswell Park Memorial Institute (RPMI)-1640 medium (Gibco-BRL; Carlsbad, CA, USA), supplemented with $10 \%$ bovine serum, penicillin $(100 \mathrm{U} / \mathrm{ml})$-streptomycin $(100 \mathrm{mg} / \mathrm{ml})$, pyruvate, glutamine and insulin at $37^{\circ} \mathrm{C}$ in a water-saturated atmosphere with $5 \% \mathrm{CO}_{2}$.

Drugs. Oxaliplatin (Oxa) and cisplatin (DDP) were supplied by the Jiangsu Hengrui Medicine Company (Jiangsu, China). The dilutions of all reagents were freshly prepared before each experiment. CellTiter 96 Aqueous One Solution Cell Proliferation Assay kit was purchased from Promega Corporation (Madison, WI, USA). Annexin-V-fluorescein isothiocyanate (FITC) Apoptosis Detection kit was purchased from Invitrogen Life Technologies (Carlsbad, CA, USA).

siRNA-mediated ERCC1 silencing. Transient knockdown of ERCC1 was achieved by transient transfection of $10 \mathrm{ng} / \mu \mathrm{l}$ ERCC1 siRNA (OriGene Technologies, Inc.; Rockville, MD, USA). AGS and MKN cells were transfected with siRNA duplexes (10 ng/ $\mu \mathrm{l})$ using Lipofectamine 2000 (Invitrogen Life Technologies) for $48 \mathrm{~h}$, according to the manufacturer's instructions, and then treated with platinum agents for $48 \mathrm{~h}$. An empty pGFP-V-RS vector and HuSH 29-mer non-effective scrambled pGFP-V-RS were used in control experiments, and were purchased from OriGene Technologies, Inc.

Cell viability assay. Cytotoxicity was determined using the CellTiter 96 Aqueous One Solution Cell Proliferation Assay kit. Briefly, tumor cells growing in the log-phase were trypsinized and seeded at $2 \times 10^{3}$ cells/well into 96 -well plates and allowed to attach overnight. The medium in each well was replaced with fresh medium or medium with various concentrations of drugs in at least six replicate wells and left to make contact for $48 \mathrm{~h}$. One-fifth of the volume of CellTiter 96 Aqueous One Solution was added to each well and incubated for an additional $3 \mathrm{~h}$. Absorbance was determined with a microplate reader (Bio-Rad; Hercules, CA, USA) at $490 \mathrm{~nm}$. The blank control wells were used for zeroing the absorbance. Each experiment was allocated 10 wells containing drug-free medium as a control. The inhibition rate (I\%) was calculated using the background-corrected absorbance by the following equation: $\mathrm{I} \%=\left(\mathrm{A}_{\text {untreated control well }}-\mathrm{A}_{\text {experimental well }}\right) / \mathrm{A}_{\text {untreated control well }} \mathrm{X} 100$. The $\mathrm{IC}_{50}$ value was defined as the concentration required for $50 \%$ inhibition of cell growth.

Apoptosis assay. The quantification of apoptotic cells was performed using an Annexin-V-FITC Apoptosis Detection kit (Invitrogen Life Technologies) according to the manufacturer's instructions. Briefly, cells were plated in a 60-mm Petri dish and allowed to grow to $75-80 \%$ confluence. Cells were exposed to ERCC1 siRNA and anticancer drugs were added singly for $48 \mathrm{~h}$ or cells were pretreated with ERCC1 siRNA for $48 \mathrm{~h}$. Subsequently, the medium was replaced with fresh medium with anticancer drugs for another $48 \mathrm{~h}$, and these were compared with control cells that had not been treated with drugs. The cells were then collected and resuspended in $500 \mu \mathrm{l}$ binding buffer, and $5 \mu \mathrm{l}$ Annexin-V-FITC and $5 \mu \mathrm{l}$ propidium iodide (PI) were added. Analyses were performed with a flow cytometer (FACSCalibur; Becton Dickinson; Franklin Lakes, NJ, USA).

Quantitative polymerase chain reaction ( $q P C R)$ assessment of ERCC1 expression. Fresh specimens were collected, grossly viewed and dissected from the primary malignant lesion by a pathologist immediately after surgical resection, and frozen within $20 \mathrm{~min}$ in liquid nitrogen. Cells were harvested with trypsin, washed with PBS and collected by centrifugation at 1,000 rpm for $5 \mathrm{~min}$. Total RNA was extracted using SV Total RNA isolation system (Promega Corporation) according to the manufacturer's instructions. The purity and quality of the mRNA were measured by a Bio-visible spectrophotometer (Eppendorf AG; Hamburg, Germany), while 1\% agarose gel electrophoresis was used to assess the integrity of the obtained RNA. cDNA with a total volume of $20 \mu \mathrm{l}$ was synthesized using the reverse transcription system containing reverse transcriptase (Promega Corporation) according to the manufacturer's instructions. Real-time qPCR of the target gene and $\beta$-actin as internal control was carried out with iCycler iQ Multicolor Real-time PCR Detection System (Bio-Rad). The $20 \mu \mathrm{l}$ PCR reaction mixture contained $1 \mathrm{X}$ primers and probe mixture [assay IDs: Hs00157415_m1 (ERCC1) and 
Hs99999903_m1 ( $\beta$-actin); Applied Biosystems, Foster City, CA, USA] and 1X Absolute QPCR mix (Abgene UK, Ltd.; Surrey, UK). The PCR conditions were $50^{\circ} \mathrm{C}$ for $2 \mathrm{~min}, 95^{\circ} \mathrm{C}$ for $15 \mathrm{~min}$, followed by 45 cycles at $95^{\circ} \mathrm{C}$ for $15 \mathrm{sec}$ and $60^{\circ} \mathrm{C}$ for $1 \mathrm{~min}$. Relative gene expression quantifications were calculated according to the comparative $\mathrm{Ct}$ method using $\beta$-actin as an endogenous control and commercial human total RNA (Clontech Laboratories, Inc.; Mountain View, CA, USA) as calibrators. Final results were determined by the $2^{-\Delta \Delta C t}$ formula, as described previously by Livak and Schmittgen (24). In the siRNA-mediated ERCC1 silencing study, equal amounts of the qRT-PCR products were also analyzed in ethidium bromidestained $1 \%$ agarose gel.

Western blot analysis. ERCC1 protein expression in cells was detected by western blot analysis. Briefly, cells were washed twice with ice-cold phosphate-buffered saline (PBS). Total protein lysates were obtained from cells using radioimmunoprecipitation assay (RIPA) cell lysis buffer (Boster, Wuhan, China). Samples were spun at $20,000 \mathrm{x} \mathrm{g}$ at $-4^{\circ} \mathrm{C}$ for $15 \mathrm{~min}$, and the supernatant was stored at $-80^{\circ} \mathrm{C}$ or immediately quantified using a protein assay (Bio-Rad). Protein lysates were electrophoresed and equal loading was assessed by Ponceau Red staining following transfer to nitrocellulose membranes. The primary antibodies used for blotting were anti-ERCC1 and anti- $\beta$-actin (OriGene Technologies, Inc.) as a loading control. The secondary antibody used was goat anti-mousehorseradish peroxidase (HRP) (Santa Cruz Biotechnology, Inc.; Santa Cruz, CA, USA). Luminescence was revealed by incubation with ECL Western blotting substrate (Promega Corporation) and signals were detected using a FluorChem SP imaging system (Alpha Innotech, San Leandro, CA, USA).

Patients and treatment protocols. Tumor specimens were collected from 75 patients with stages Ib-IV (M0) who were recruited during the period from January, 2005 to June, 2007 and underwent surgery at the Department of Gastroenterological Surgery, Changzhou Tumor Hospital. The patients comprised 53 males and 22 females, ranging in age from 36-73 years, with a median age of 58 years. None of the patients had previously received chemotherapy. This study had been approved by the local ethics committees, and written informed consent was obtained from all patients. Following surgery, 57 patients received $\geq 6$ cycles of oxaliplatin at $85 \mathrm{mg} / \mathrm{m}^{2}$ plus leucovorin at $20 \mathrm{mg} / \mathrm{m}^{2}$ on the first day of treatment, followed by $5-\mathrm{FU}$, via a $400 \mathrm{mg} / \mathrm{m}^{2}$ bolus, and a $22 \mathrm{~h}$ continuous infusion of $600 \mathrm{mg} / \mathrm{m}^{2} 5$-FU on Days 1-2 at 2-week intervals. Twenty-three patients received surgery alone.

Follow-up. Interim history, physical examination, hematological studies, carcinoembryonic antigen levels and whole-body computed tomography were conducted every 3 months in the first year and every 6 months thereafter. Patients underwent upper endoscopy 6 months after surgery and every 12 months thereafter. Recurrences or metastases of gastric carcinoma were determined by cytology biopsy, surgery or whole-body computed tomography. The American Joint Committee on Cancer (AJCC) 7th Edition of Gastric Cancer was used for the classification of each case. The study was implemented in a blind fashion; the patient outcome was unknown to

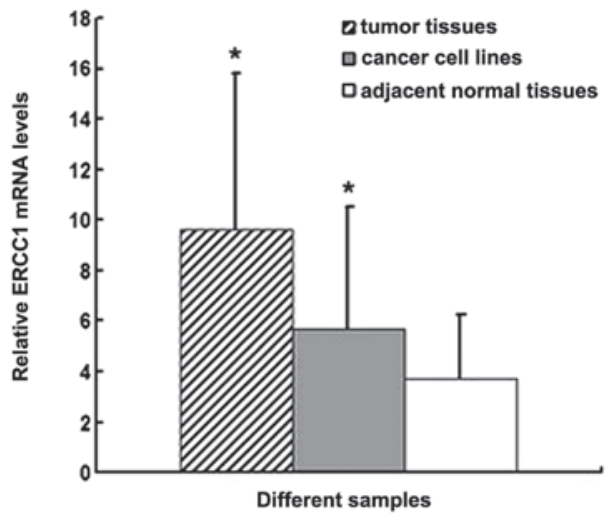

Figure 1. Relative excision repair cross-complementing 1 (ERCC1) mRNA levels among gastric cancer tissues, cancer cell lines and adjacent normal tissues. ERCC1 mRNA was more highly expressed in cancer tissues and cancer cell lines compared with adjacent normal tissues $\left({ }^{*} \mathrm{P}<0.05\right)$.

investigators performing the molecular analyses. Relapse-free survival (RFS) was the time period from study initiation until disease recurrence or death or the day of the last follow-up visit (whichever of these occurred first). Overall survival (OS) was the time period from study initiation until the date of mortality, regardless of the cause, or until the most recently documented follow-up.

Statistical analysis. Statistical significance was based on a two-sided significance level of 0.05. All analyses were performed with the Statistical Package for the Social Sciences (SPSS), version 13.0 (SPSS, Inc.; Chicago, IL, USA). The Spearman's correlation coefficient was adopted to analyze the correlation between gene expression levels and drug sensitivity. Statistical comparisons were performed using the Student's t-test. To test for correlations between gene expression levels and the clinical variables, dichotomization of the gene expression values as equal/above and below the median expression value were conducted and tested by the $\chi^{2}$ test or Fisher's exact test (two-sided), as appropriate. Kaplan-Meier survival curves and the log-rank test were used to analyze univariate distributions for RFS and OS. The prognostic significance of ERCC1 following adjustment for other prognostic factors was assessed using a Cox proportional hazards regression model.

\section{Results}

ERCCl expression level is correlated with the chemosensitivity of platinum agents in gastric cancer cell lines. The ERCC1 expression levels were first examined in 7 gastric cancer cell lines, tumor tissues and adjacent normal tissues by qRT-PCR. ERCC1 mRNA levels in gastric cancer cell lines and gastric cancer tissues were significantly higher than those in adjacent normal tissues $(\mathrm{P}<0.05$; Fig. 1). No significant differences were observed between gastric cancer cell lines and gastric cancer tissues.

The correlation between ERCC1 mRNA expression levels and the chemosensitivity of platinum agents in 7 gastric cancer cell lines was subsequently determined. We found that ERCC1 mRNA expression levels were positively correlated with the 
A

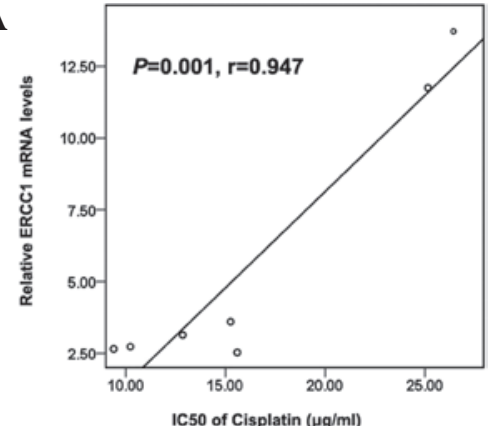

B

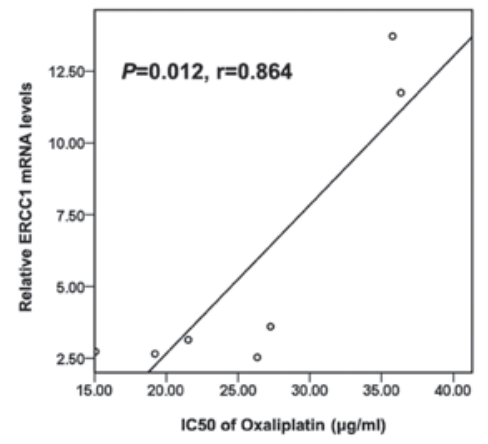

Figure 2. Excision repair cross-complementing 1 (ERCC1) expression levels are correlated with the chemosensitivity of platinum agents in gastric cancer cell lines. (A) ERCC1 mRNA expression levels are positively correlated with the $\mathrm{IC}_{50}$ value of cisplatin in 7 gastric cancer cell lines $(\mathrm{P}=0.001 ; \mathrm{r}=0.947)$. (B) ERCC1 mRNA expression levels are positively correlated with the $\mathrm{IC}_{50}$ value of oxaliplatin in 7 gastric cancer cell lines $(\mathrm{P}=0.012 ; \mathrm{r}=0.864)$.

$\mathrm{IC}_{50}$ value of cisplatin ( $\mathrm{P}=0.001 ; \mathrm{r}=0.947$; Fig. $2 \mathrm{~A}$ ) and oxaliplatin ( $\mathrm{P}=0.012$; $\mathrm{r}=0.864$; Fig. $2 \mathrm{~B})$, respectively.

Inhibition of ERCC1 by siRNA sensitizes gastric cancer cell lines to cisplatin and oxaliplatin. To further examine the functional role of ERCC1 in gastric cancer cells, the relatively resistant MKN45 cells were transfected with siRNA duplexes against ERCC1. In MKN45 cell lines, successful knockdown of ERCC1 expression was confirmed by qRT-PCR and western blot analysis (Fig. 3). Downregulation of ERCC1 by siRNA did not result in significant suppression of cell proliferation following transfection for $48 \mathrm{~h}$, while siRNA-mediated attenuation of ERCC1 expression led to a subsequent sensitizing effect to cisplatin and oxaliplatin by an early apoptosis test (Fig. 4). The CellTiter 96 Aqueous One Solution Cell Proliferation test demonstrated that downregulation of ERCC1 by siRNA decreased the $\mathrm{IC}_{50}$ value of cisplatin from $26.44 \pm 2.72$ to $2.12 \pm 0.31 \mu \mathrm{g} / \mathrm{ml}(\mathrm{P}<0.001)$ and that of oxaliplatin from $35.77 \pm 3.82$ to $7.12 \pm 0.72 \mu \mathrm{g} / \mathrm{ml}(\mathrm{P}=0.003)$. These results suggest that the ERCC1 expression level is important for cell viability against platinum-based drugs, and that the expression of ERCC1 siRNA effectively increased the sensitivity to these drugs.

Expression levels of ERCC1 $\mathrm{mRNA}$ are correlated with clinicopathological characteristics. The expression of ERCC1 mRNA was evaluable in all 75 patients, and the median value was 7.32 (range $0.50-147.03$ ). Table I summarizes the characteristics of the study population. Patients were divided into two groups centered about the median value; 38 patients with high ERCC1 levels and 37 with low ERCC1 levels. High
A
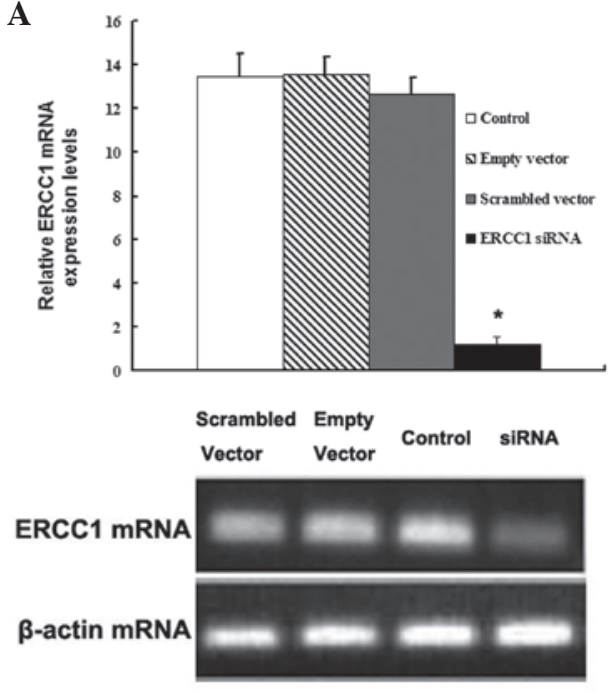

B

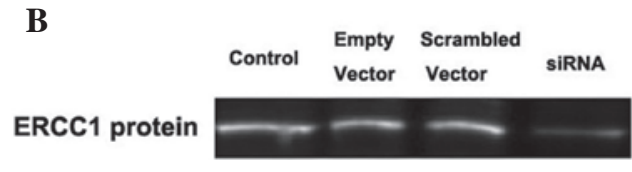

Figure 3. Effect of siRNA on excision repair cross-complementing 1 (ERCC1) mRNA and protein expression in the MKN45 cells. (A) ERCC1 siRNA significantly downregulated the expression level of ERCC1 mRNA in MKN45 cells ( ${ }^{*} \mathrm{P}<0.05$, compared with the untreated control group). (B) ERCC1 siRNA significantly downregulated the expression level of ERCC1 protein in MKN45 cells.
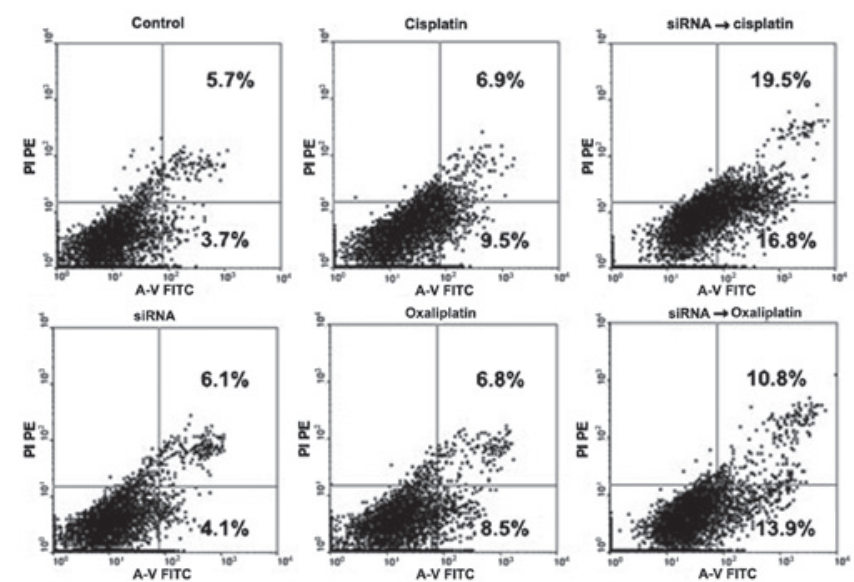

Figure 4. Effect of siRNA-mediated downregulation of excision repair crosscomplementing 1 (ERCC1) on early apoptosis rates in relatively resistant MKN45 cell line. The cells were treated with ERCC1 siRNA (10 ng/ $/ \mu 1)$ and platinum agents (IC20) alone for $48 \mathrm{~h}$, or transfected with $10 \mathrm{ng} / \mu 1 \mathrm{ERCC} 1$ siRNA for $48 \mathrm{~h}$, then followed by platinum agents for another $48 \mathrm{~h}$. The apoptotic effect of the drugs was evaluated by double staining with both Annexin-V-fluorescein isothiocyanate (FITC) and propidium iodide (PI).

ERCC1 expression was more common in younger patients (60.5\% for younger patients vs. $37.8 \%$ for elderly patients; $\mathrm{P}=0.049$ ). No other correlations were observed between the clinical characteristics and ERCC1 expression levels (Table I).

Expression levels of ERCC1 $m R N A$ are correlated with survival in patients receiving surgery followed by FOLFOX adjuvant chemotherapy. The median RFS was 12.5 months 
Table I. Correlations between ERCC1 expression levels and clinical variables.

\begin{tabular}{|c|c|c|c|c|}
\hline \multirow[b]{2}{*}{ Variables } & \multicolumn{2}{|c|}{ ERCC1 expression level } & \multirow[b]{2}{*}{ Total } & \multirow[b]{2}{*}{ P-value } \\
\hline & $\operatorname{High}(\%)$ & Low $(\%)$ & & \\
\hline Gender & & & & 0.276 \\
\hline Male & $24(45.3)$ & $29(54.7)$ & $53(100)$ & \\
\hline Female & $13(59.1)$ & $9(40.9)$ & $22(100)$ & \\
\hline Age (years) (median) & & & & 0.049 \\
\hline$\leq 58$ & $23(60.5)$ & $15(39.5 \%)$ & $38(100)$ & \\
\hline$>58$ & $14(37.8)$ & $23(62.2 \%)$ & $37(100)$ & \\
\hline Tumor differentiation & & & & 0.537 \\
\hline Well & $15(57.7)$ & $11(42.3)$ & $26(100)$ & \\
\hline Moderate & $17(43.6)$ & $22(56.4)$ & $39(100)$ & \\
\hline Poor or undifferentiated & $5(50.0)$ & $5(50.0)$ & $10(100)$ & \\
\hline Site of tumor & & & & 0.427 \\
\hline Proximal stomach & $12(50.0)$ & $12(50.0)$ & $24(100)$ & \\
\hline Stomach body & $10(62.5)$ & $6(37.5)$ & $16(100)$ & \\
\hline Distal stomach & $15(42.9)$ & $20(57.1)$ & $35(100)$ & \\
\hline Staging & & & & 0.311 \\
\hline I and II & $9(56.3)$ & $7(43.7)$ & $16(100)$ & \\
\hline III & $13(39.4)$ & $20(60.6)$ & $33(100)$ & \\
\hline IV & $15(57.7)$ & $11(42.3)$ & $26(100)$ & \\
\hline Carcinoembryonic antigen $(\mathrm{ng} / \mathrm{ml})$ & & & & 0.296 \\
\hline$\leq 5$ & $21(44.7)$ & $26(55.3)$ & $47(100)$ & \\
\hline$>5$ & $16(57.1)$ & $12(42.9)$ & $28(100)$ & \\
\hline
\end{tabular}

ERCC1, excision repair cross-complementation group 1.
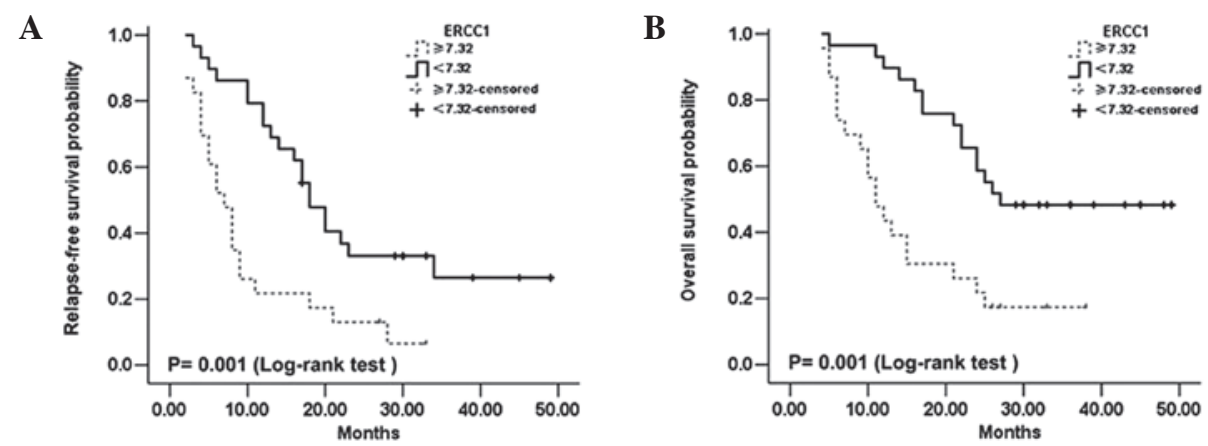

Figure 5. Relapse-free survival curve (A) and overall survival curve (B) in patients treated with oxaliplatin-based adjuvant chemotherapy, according to excision repair cross-complementing 1 (ERCC1) expression equal/above and below the median ERCC1 level. Patients with ERCC1 levels below the median had significantly longer median RFS and OS times compared with patients with ERCC1 levels equal/above the median (median RFS, 18 vs. 7 months; median OS, 27 vs. 11 months, respectively).

(range, 2-49 months), and the median OS time was 22 months (range, 4-49 months). Table II demonstrates that ERCC1 expression is significantly correlated with both RFS $(\mathrm{P}=0.001)$ and $\mathrm{OS}(\mathrm{P}=0.001)$ time, Fig. 5A and $\mathrm{B}$ show the Kaplan-Meier survival curve for patients with intratumoral ERCC1 levels equal/above and below the median ERCC1 level. Patients with ERCC1 levels below the median had a significantly longer median RFS and median OS times compared with patients with ERCC1 levels equal/above the median (median RFS, 18 vs. 7 months; median OS, 27 vs. 11 months), respectively.
Other factors that were significantly correlated with RFS and OS in the univariate analysis by the Kaplan-Meier survival curves and the log-rank test included age, tumor stage and the levels of serum carcinoembryonic antigen (Table II). Gender, tumor differentiation and tumor location were not significant prognostic factors for either RFS and OS. ERCC1 levels, stage and serum carcinoembryonic antigen remained significant prognostic factors correlated with RFS and OS in the Cox proportional hazards regression model multivariate analysis (Table III). 
Table II. Factors correlated with survival in patients receiving surgery followed by oxaliplatin-based adjuvant chemotherapy.

\begin{tabular}{|c|c|c|c|c|c|}
\hline & $\mathrm{n}$ & M-RFS (months) & P-value & MST (months) & P-value \\
\hline Gender & & & 0.526 & & 0.408 \\
\hline Male & 37 & 14 & & 24 & \\
\hline Female & 15 & 9 & & 21 & \\
\hline Age (years) & & & 0.017 & & 0.019 \\
\hline$\leq 58$ & 25 & 8 & & 15 & \\
\hline$>58$ & 27 & 18 & & & \\
\hline Tumor differentiation & & & 0.652 & & 0.419 \\
\hline Well & 20 & 17 & & 22 & \\
\hline Moderate & 25 & 12 & & 22 & \\
\hline Undifferentiated & 7 & 8 & & 15 & \\
\hline Tumor location & & & 0.484 & & 0.598 \\
\hline Proximal stomach & 14 & 10 & & 17 & \\
\hline Stomach body & 10 & 13 & & 21 & \\
\hline Distal stomach & 28 & 16 & & 24 & \\
\hline Staging & & & $<0.001$ & & $<0.001$ \\
\hline I, II and III & 32 & 18 & & & \\
\hline IV & 20 & 6 & & 11 & \\
\hline ERCC1 level & & & 0.001 & & 0.001 \\
\hline$<7.32$ & 29 & 18 & & 27 & \\
\hline$\geq 7.32$ & 23 & 7 & & 12 & \\
\hline Carcinoembryonic antigen $(\mathrm{ng} / \mathrm{ml})$ & & & $<0.001$ & & $<0.001$ \\
\hline$\leq 5$ & 33 & 18 & & 27 & \\
\hline$>5$ & 19 & 6 & & 12 & \\
\hline
\end{tabular}

ERCC1, excision repair cross-complementation group 1; M-RFS, median relapse-free survival; MST, median survival time.

Table III. Hazard ratios for relapse-free survival and overall survival in patients receiving adjuvant chemotherapy.

\begin{tabular}{|c|c|c|c|c|c|c|}
\hline \multirow[b]{2}{*}{ Prognostic factors } & \multicolumn{3}{|c|}{ RFS } & \multicolumn{3}{|c|}{ OS } \\
\hline & HR & $95 \% \mathrm{CI}$ & P-value & HR & $95 \% \mathrm{CI}$ & P-value \\
\hline ERCC1 level & & & 0.026 & & & 0.031 \\
\hline$<7.32$ & 1 & & & 1 & & \\
\hline$\geq 7.32$ & 2.16 & $1.09-4.25$ & & 2.21 & $1.07-4.55$ & \\
\hline Staging & & & 0.002 & & & 0.010 \\
\hline I, II and III & 1 & & & 1 & & \\
\hline IV & 3.12 & $1.52-6.42$ & & 2.81 & $1.29-6.15$ & \\
\hline Carcinoembryonic antigen (ng/ml) & & & 0.012 & & & 0.050 \\
\hline$\leq 5$ & 1 & & & 1 & & \\
\hline$>5$ & 2.49 & $1.23-5.09$ & & 2.16 & $0.99-4.68$ & \\
\hline
\end{tabular}

ERCC1, excision repair cross-complementation group 1; RFS, relapse-free survival; OS, overall survival; HR, hazard ratio; CI, confidence interval.

\section{Discussion}

Platinum-based chemotherapy remains the backbone of therapy in the management of advanced gastric cancer. Recently, oxaliplatin, a third platinum analog, has been widely used in patients with gastric cancer (25). A small number of studies have demonstrated that the combination of oxaliplatin and 5-FU modulated with LV obtained an objective response rate of $38-55 \%$ in gastric cancer patients $(9-13,26)$. However, this implies that $\sim 50 \%$ of patients suffered the toxic effects 
of this regimen without obtaining any real benefit. Therefore, predictive markers are required to identify those patients likely to benefit from oxaliplatin-based treatment in gastric cancer.

The cytotoxic effects of cisplatin and oxaliplatin are principally attributable to the formation of bulky platinum-DNA adducts $(7,27)$, and these adducts are recognized and repaired by the nucleotide excision repair (NER) pathway. The ERCC1 protein is major component of the NER complex, acting as the rate-limiting enzyme in the NER pathway, while high expression of ERCC1 has been demonstrated to be correlated with poor responses to chemotherapy in various tumor types (19,28-33).

In our study, we found the ERCC1 expression levels were inversely associated with the chemosensitivity of platinum agents in 7 gastric cancer cell lines, and the inhibition of ERCC1 expression by siRNA sensitized the effects of cisplatin and oxaliplatin in the relatively resistant MKN45 cells. These results were partially consistent with those of other studies $(28,34,35)$. The mechanisms whereby ERCC1 participates in platinum resistance in cancer cells has been demonstrated to be correlated with increased removal of the platinum-DNA adducts and interstrand cross-links (36-38).

Several studies have investigated the influence of ERCC1 in resistance to platinum compound in gastric cancer patients, and the majority of which revealed that patients with low levels of ERCC1 protein or mRNA expression were associated with favorable clinical outcomes of platinum based anti-cancer chemotherapy $(32,39,40)$. This suggests that ERCC1 is a predictive marker for clinical resistance to platinum compounds. Our results demonstrated that patients with low ERCC1 levels had longer RFS and OS times than those with high ERCC1 levels, and the multivariate analysis suggested that ERCC1 expression is an independent predictive marker associated with RFS and OS, which is consistent with the studies mentioned previously. By contrast, other studies have demonstrated that low ERCC1 expression was correlated with poor survival (41) or exhibited no correlation with survival (42). Conflicting results between different studies may be related to biological variations of the analyzed tumors, or to variations with respect to the chemotherapeutic protocol or to the different techniques for testing ERCC1 expression.

We also investigated the correlation between ERCC1 expression levels and clinicopathological characteristics. A significant correlation was only observed between ERCC1 expression levels and age ( $\mathrm{P}=0.049)$, and high ERCC1 expression was more common in younger patients $(60.5 \%$ for younger patients vs. $37.8 \%$ for elderly patients), which may explain why younger patients had poorer RFS and OS times than elderly patients, following oxaliplatin-based adjuvant chemotherapy (median RFS, 8 vs. 18 months, $\mathrm{P}=0.017$; median OS, 15 months vs. undefined, $\mathrm{P}=0.019$, respectively; Table II).

One limitation of the present study is the relatively small sample size. Moreover, the majority of patients who received surgery alone belonged to stages II and III, but were not willing to receive the adjuvant chemotherapy or radiotherapy. Due to the imbalance in the distribution of clinical stage and the inadequate sample size, we did not compare survival times between patients receiving adjuvant chemotherapy and those treated with surgery alone.
In conclusion, the present results support the theories that ERCC1 may participate in platinum resistance in gastric cancer cells, and that high ERCC1 expression may be a poor predictor of efficient oxaliplatin-based adjuvant chemotherapy. To further confirm the prognostic value of tumor ERCC1 expression in gastric cancer, a multi-center prospective study with a large sample size is required in our future investigations.

\section{Acknowledgements}

This study was partly supported by the Science and Technology Planning Project of Changzhou, Jiangsu Province (CS20092025), the Research of Health Department in Jiangsu Province (Z201221), the Science and Technology Planning Project of Changzhou Health Bureau, Jiangsu Province (QN201106 and ZD201203), the 333 Talents Training Project of Jiangsu Province, the Key Medical Innovation Talents Training Project of Changzhou, Jiangsu Province, and the Project of Jiangsu Province Sanitation Innovation Team.

\section{References}

1. Leung WK, Wu MS, Kakugawa Y, et al: Screening for gastric cancer in Asia: current evidence and practice. Lancet Oncol 9: 279-287, 2008.

2. Kamangar F, Dores GM and Anderson WF: Patterns of cancer incidence, mortality, and prevalence across five continents: defining priorities to reduce cancer disparities in different geographic regions of the world. J Clin Oncol 24: 2137-2150, 2006.

3. Macdonald JS: Treatment of localized gastric cancer. Semin Oncol 31: 566-573, 2004.

4. Carrato A, Gallego-Plazas J and Guillen-Ponce C: Adjuvant therapy of resected gastric cancer is necessary. Semin Oncol 32: S105-S108, 2005.

5. Chipponi J, Huguier M, Pezet D, et al: Randomized trial of adjuvant chemotherapy after curative resection for gastric cancer. Am J Surg 187: 440-445, 2004.

6. Topuz E, Basaran M, Saip P, et al: Adjuvant intraperitoneal chemotherapy with cisplatinum, mitoxantrone, 5-fluorouracil, and calcium folinate in patients with gastric cancer: a phase II study. Am J Clin Oncol 25: 619-624, 2002.

7. Mamenta EL, Poma EE, Kaufmann WK, Delmastro DA, Grady HL and Chaney SG: Enhanced replicative bypass of platinum-DNA adducts in cisplatin-resistant human ovarian carcinoma cell lines. Cancer Res 54: 3500-3505, 1994.

8. Extra JM, Espie M, Calvo F, Ferme C, Mignot L and Marty M: Phase I study of oxaliplatin in patients with advanced cancer. Cancer Chemother Pharmacol 25: 299-303, 1990.

9. Louvet C, André T, Tigaud JM, et al: Phase II study of oxaliplatin, fluorouracil, and folinic acid in locally advanced or metastatic gastric cancer patients. J Clin Oncol 20: 4543-4548, 2002.

10. De Vita F, Orditura M, Matano E, et al: A phase II study of biweekly oxaliplatin plus infusional 5-fluorouracil and folinic acid (FOLFOX-4) as first-line treatment of advanced gastric cancer patients. Br J Cancer 92: 1644-1649, 2005.

11. Al-Batran SE, Atmaca A, Hegewisch-Becker S, et al: Phase II trial of biweekly infusional fluorouracil, folinic acid, and oxaliplatin in patients with advanced gastric cancer. J Clin Oncol 22: 658-663, 2004.

12. Lordick F, Lorenzen S, Stollfuss J, et al: Phase II study of weekly oxaliplatin plus infusional fluorouracil and folinic acid (FUFOX regimen) as first-line treatment in metastatic gastric cancer. $\mathrm{Br}$ J Cancer 93: 190-194, 2005.

13. Cavanna L, Artioli F, Codignola C, et al: Oxaliplatin in combination with 5-fluorouracil (5-FU) and leucovorin (LV) in patients with metastatic gastric cancer (MGC). Am J Clin Oncol 29: 371-375, 2006.

14. Wei Q, Frazier ML and Levin B: DNA repair: a double-edged sword. J Natl Cancer Inst 92: 440-441, 2000.

15. Woynarowski JM, Faivre S, Herzig MC, et al: Oxaliplatininduced damage of cellular DNA. Mol Pharmacol 58: 920-927, 2000 . 
16. Reed E: ERCC1 and clinical resistance to platinum-based therapy. Clin Cancer Res 11: 6100-6102, 2005.

17. Nuñez F, Chipchase MD, Clarke AR and Melton DW: Nucleotide excision repair gene (ERCC1) deficiency causes $\mathrm{G}(2)$ arrest in hepatocytes and a reduction in liver binucleation: the role of p53 and p21. FASEB J 14: 1073-1082, 2000.

18. Cobo M, Isla D, Massuti B, et al: Customizing cisplatin based on quantitative excision repair cross-complementing $1 \mathrm{mRNA}$ expression: a phase III trial in non-small-cell lung cancer. J Clin Oncol 25: 2747-2754, 2007.

19. Olaussen KA, Dunant A, Fouret P, et al: DNA repair by ERCC1 in non-small-cell lung cancer and cisplatin-based adjuvant chemotherapy. N Engl J Med 355: 983-991, 2006.

20. Weberpals J, Garbuio K, O'Brien A, et al: The DNA repair proteins BRCA1 and ERCC1 as predictive markers in sporadic ovarian cancer. Int J Cancer 124: 806-815, 2009.

21. Denlinger CS and Cohen SJ: Progress in the development of prognostic and predictive markers for gastrointestinal malignancies. Curr Treat Options Oncol 8: 339-351, 2007.

22. Iqbal S, Stoehlmacher J and Lenz HJ: Tailored chemotherapy for colorectal cancer: a new approach to therapy. Cancer Invest 22: 762-773, 2004

23. Höfler H, Langer R, Ott K and Keller G: Prediction of response to neoadjuvant chemotherapy in carcinomas of the upper gastrointestinal tract. Adv Exp Med Biol 587: 115-120, 2006.

24. Livak KJ and Schmittgen TD: Analysis of relative gene expression data using real-time quantitative PCR and the 2(-Delta Delta C(T)) Method. Methods 25: 402-408, 2001.

25. Boku N: Perspectives for personalization in chemotherapy of advanced gastric cancer. Discov Med 9: 84-89, 2010.

26. Mauer AM, Kraut EH, Krauss SA, et al: Phase II trial of oxaliplatin, leucovorin and fluorouracil in patients with advanced carcinoma of the esophagus. Ann Oncol 16: 1320-1325, 2005.

27. Suo Z, Lippard SJ and Johnson KA: Single d(GpG)/ cis-diammineplatinum(II) adduct-induced inhibition of DNA polymerization. Biochemistry 38: 715-726, 1999.

28. Selvakumaran M, Pisarcik DA, Bao R, Yeung AT and Hamilton TC: Enhanced cisplatin cytotoxicity by disturbing the nucleotide excision repair pathway in ovarian cancer cell lines. Cancer Res 63: 1311-1316, 2003.

29. Sun JM, Ahn MJ, Park MJ, et al: Expression of excision repair cross-complementation group 1 as predictive marker for nasopharyngeal cancer treated with concurrent chemoradiotherapy. Int J Radiat Oncol Biol Phys 80: 655-660, 2011.

30. Hwang IG, Ahn MJ, Park BB, et al: ERCC1 expression as a prognostic marker in $\mathrm{N} 2(+)$ nonsmall-cell lung cancer patients treated with platinum-based neoadjuvant concurrent chemoradiotherapy. Cancer 113: 1379-1386, 2008.
31. Jun HJ, Ahn MJ, Kim HS, et al: ERCC1 expression as a predictive marker of squamous cell carcinoma of the head and neck treated with cisplatin-based concurrent chemoradiation. Br J Cancer 99: 167-172, 2008

32. Kwon HC, Roh MS, Oh SY, et al: Prognostic value of expression of ERCC1, thymidylate synthase, and glutathione S-transferase P1 for 5-fluorouracil/oxaliplatin chemotherapy in advanced gastric cancer. Ann Oncol 18: 504-509, 2007.

33. Kim MK, Cho KJ, Kwon GY, et al: ERCC1 predicting chemoradiation resistance and poor outcome in oesophageal cancer. Eur J Cancer 44: 54-60, 2008.

34. Chang IY, Kim MH, Kim HB, et al: Small interfering RNA-induced suppression of ERCC1 enhances sensitivity of human cancer cells to cisplatin. Biochem Biophys Res Commun 327: 225-233, 2005

35. Song L, Ritchie AM, McNeil EM, Li W and Melton DW: Identification of DNA repair gene Ercc1 as a novel target in melanoma. Pigment Cell Melanoma Res 24: 966-971, 2011.

36. Sancar A: Excision repair in mammalian cells. J Biol Chem 270: 15915-15918, 1995

37. Darcy KM, Tian C and Reed E: A Gynecologic Oncology Group study of platinum-DNA adducts and excision repair cross-complementation group 1 expression in optimal, stage III epithelial ovarian cancer treated with platinum-taxane chemotherapy. Cancer Res 67: 4474-4481, 2007.

38. Kudo K, Gavin E, Das S, Amable L, Shevde LA and Reed E: Inhibition of Gli1 results in altered c-Jun activation, inhibition of cisplatin-induced upregulation of ERCC1, XPD and XRCC1, and inhibition of platinum-DNA adduct repair. Oncogene 31: 4718-4724, 2012

39. Wei J, Zou Z, Qian X, et al: ERCC1 mRNA levels and survival of advanced gastric cancer patients treated with a modified FOLFOX regimen. Br J Cancer 98: 1398-1402, 2008.

40. Matsubara J, Nishina T, Yamada Y, et al: Impacts of excision repair cross-complementing gene 1 (ERCC1), dihydropyrimidine dehydrogenase, and epidermal growth factor receptor on the outcomes of patients with advanced gastric cancer. Br J Cancer 98: 832-839, 2008

41. Kim JS, Kim MA, Kim TM, et al: Biomarker analysis in stage III-IV (M0) gastric cancer patients who received curative surgery followed by adjuvant 5-fluorouracil and cisplatin chemotherapy: epidermal growth factor receptor (EGFR) associated with favourable survival. Br J Cancer 100: 732-738, 2009.

42. Napieralski R, Ott K, Kremer M, et al: Combined GADD45A and thymidine phosphorylase expression levels predict response and survival of neoadjuvant-treated gastric cancer patients. Clin Cancer Res 11: 3025-3031, 2005. 